\title{
Superior Thyroid Artery Arising From the Common Carotid Artery- Potential Source for Unpredicted Intraoperative Bleeding- A Cadaveric Case Report
}

\author{
Balaiya Anitha ${ }^{1}$, Shanthini ${ }^{1}$ \\ ${ }^{1}$ Assistant Professor, Department of Anatomy, Sri Lakshminarayana Institute of Medical Sciences, Puducherry, India.
}

\section{Abstract}

\begin{abstract}
Superior thyroid artery usually arises from the anterior surface of external carotid artery as its first branch. Superior thyroid artery forms an important collateral circulation in case of unilateral occlusion of common carotid artery. Due to the close relation with superior thyroid artery, external laryngeal nerve is prone to injury during thyroid surgery. Superior thyroid artery occasionally arises from the bifurcation of common carotid artery or from the common carotid artery. In the present cadaveric case, during the routine neck dissection of the cadaver in department of anatomy, anomalous origin of the left superior thyroid artery was found. It was originating from the left common carotid artery at a distance of $1.8 \mathrm{~cm}$ proximal to the bifurcation of common carotid artery. The length of left superior thyroid artery was $3.2 \mathrm{~cm}$. left Inferior thyroid artery was present and no anomaly was found. Right superior and inferior thyroid arteries were present and no variations were found. Knowledge about these variations in the origin of superior thyroid artery is extremely important in head and neck surgeries to prevent inadvertant injury and avoid torrential bleeding.
\end{abstract}

Keywords: Superior thyroid artery, Neck surgery, Anatomical variations, Anomalous artery, Intraoperative bleeding.

Corresponding Author: Dr. B. Anitha, Assistant Professor, Department of Anatomy, Sri Lakshminarayana Institute of Medical Sciences, Pondicherry-605006, India.

Received: August 2019

Accepted: August 2019

\section{Introduction}

Superior thyroid artery usually arises from the anterior surface of external carotid artery as its first branch. Branches of superior thyroid artery include infrahyoid, superior laryngeal, sternocleidomastoid, cricothyroid, glandular branches. Glandular branches give anterior and posterior branches over the thyroid. ${ }^{[1]}$ The anterior branch anastomosis with its fellow branch from the opposite side at the upper border of isthmus and the posterior branch anastomoses with the inferior thyroid artery. Superior thyroid artery forms an important collateral circulation in case of unilateral occlusion of common carotid artery. ${ }^{[1-3]}$ Due to the close relation with superior thyroid artery, external laryngeal nerve is prone to injury during thyroid surgery. Superior thyroid artery occasionally arises from the bifurcation of common carotid artery or from the common carotid artery. Knowledge about these variations in the origin of superior thyroid artery is extremely useful in head and neck surgeries to prevent inadvertant injury. Here we are presenting a case in which left superior thyroid artery is arising from left common carotid artery.

\section{Case Report}

During the routine neck dissection of the cadaver in department of anatomy, anomalous origin of the left superior thyroid artery was found. It was originating from the left common carotid artery at the level of upper border of thyroid cartilage. After arising from left common carotid artery it was descending vertically downwards along the lateral border of thyrohyoid muscle along with the external laryngeal nerve [Figure 1].

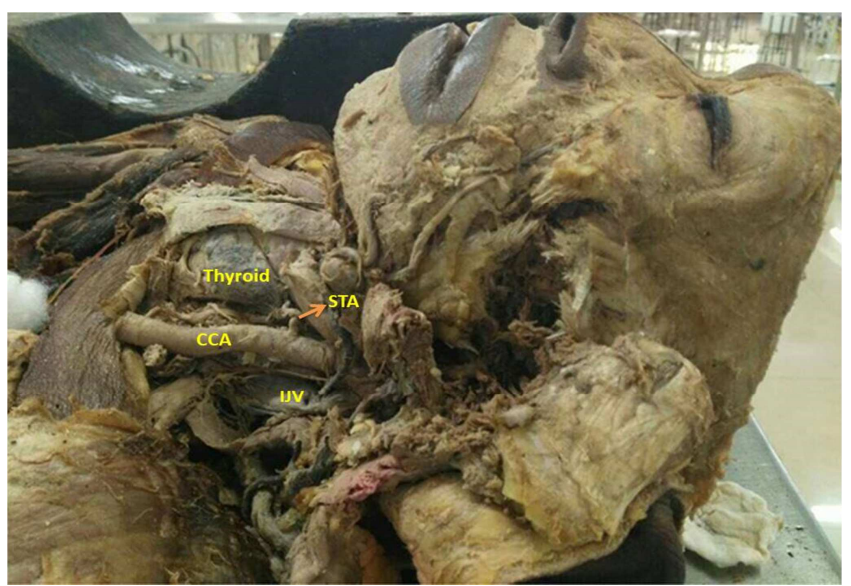

Figure 1: Anomalous origin of left superior thyroid artery from left common carotid artery. STA-superior thyroid artery, CCA-common carotid artery, ECA-external carotid artery, ICA- internal carotid artery, IJV- internal jugular vein 
External laryngeal nerve was found to lie posteromedial to superior thyroid artery and reached deep surface of thyroid gland. Superior thyroid artery reached the apex of the thyroid lobe. Common carotid bifurcation was found above the level of lamina of thyroid cartilage. Superior thyroid artery originated at a distance of $1.8 \mathrm{~cm}$ proximal to the bifurcation of common carotid artery. The length of left superior thyroid artery was $3.2 \mathrm{~cm}$ [Figure 2]. Left Inferior thyroid artery was present and no anomaly was found. Right superior and inferior thyroid arteries were present and no variations were found.

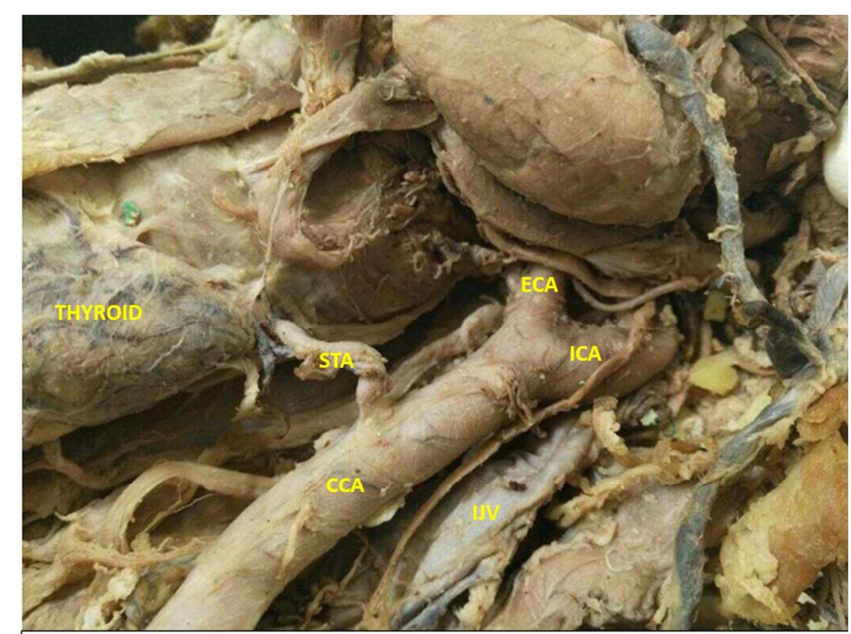

Figure 2: Origin of left superior thyroid artery from common carotid artery and the bifurcation of common carotid artery. STA-superior thyroid artery, CCA-common carotid artery, ECA-external carotid artery, ICA- internal carotid artery, IJVinternal jugular vein

\section{Discussion}

Superior thyroid artery usually arises from the anterior aspect of external carotid artery as its first branch. It can also arise from the bifurcation of common carotid artery or from the common carotid artery. Rarely superior thyroid artery may be absent. Branches from this artery supplies thyroid gland, infrahyoid strap muscles, upper part of the larynx, middle region of sternocleidomastoid and cricothyroid. ${ }^{[4]}$

According to a study, by Joshi et al, the most common origin of the superior thyroid artery is from external carotid artery (in $66.67 \%$ cases), in $31.81 \%$ of cases from common carotid bifurcation and in $1.51 \%$ of cases is from common carotid artery. ${ }^{[2]}$ A study by Shivaleela $\mathrm{C}$ et al conducted on 42 cadavers, the origin of superior thyroid artery from external carotid was found in $76.19 \%$, in $21.43 \%$ of the cases the origin was from the common carotid bifurcation and in $2.38 \%$ of the cases the origin was from common carotid artery. ${ }^{[3]}$

According to a study by Manjunath C S, conducted on 15 adult cadavers, origin of superior thyroid artery was found to be from external carotid artery in $60 \%$ of cases, from common carotid bifurcation in $23.3 \%$ and from common carotid in $16.66 \%$ of cases. Rarely it arises from subclavian artery and it is absent in extremely rare cases. ${ }^{[4]}$
Dessieet al conducted study on 43 cadavers shows superior thyroid artery arising from common carotid artery in 23 cases. ${ }^{[5]}$ This associated with high bifurcation of common carotid artery. In $90 \%$ of cases common carotid artery bifurcates above the lamina of thyroid cartilage and it is associated with superior thyroid artery arising from common carotid artery. ${ }^{[6-9]}$

The knowledge of all these variations and its relationship with the surrounding structures is extremely important in head and neck surgeries. Due to the close relation to superior thyroid artery, chances of injuring external laryngeal nerve are high. ${ }^{[8,9]}$ Lack of knowledge of these variations can lead to fatal errors in neck surgeries. The most dreaded complication of radical neck surgery is injury to superior thyroid artery and its branches. ${ }^{[9,10]}$ The knowledge of these variations will be helpful in various surgical procedures of the neck like thyroid surgeries, radical neck dissection, reconstruction surgeries for aneurysm and carotid endarterectomy. ${ }^{[6-9]}$

\section{Conclusion}

A profound knowledge of all the possible variations in the superior thyroid artery origin, branching and course will be helpful in carrying out various surgical procedures in the neck safely. Iatrogenic injuries can be minimised with a sound knowledge of these variations and will be helpful in good surgical outcomes.

\section{References}

1. Standring, S. (Ed). Gray's Anatomy: The Anatomical Basis of Clinical Practice 41ST ed. NewYork: Churchill Livingstone.2008; P453.

2. Joshi A, Gupta S, Vaniya VH . Anatomical variation in the origin of superior thyroid artery and it's relation with external laryngeal nerve. National J of medical research 2014; 4:138-141

3. Shivaleela C, Anupama D, Subhash RLP. Study of anatomical variations in the origin of superior thyroid artery. Int J Anat Res 2016; 4(1):1765-68

4. Manjunath C S, Lokanathan TH . Anatomical variations in the origin of superior thyroid artery and its clinical significance. Int J Anat Res 2016; 4(3):2656-68.

5. Dessie MA Variations of the origin of superior thyroid artery and its relationship with the external branch of superior laryngeal nerve. PLoS one 2018;13(5): e0197075.

6. Jitendra P Patel, Rashmikant V Dave, Ritesh K Shah, Sanjay D Kanani, Ashok B Nirvan A Study Of Superior Thyroid Artery In 50 Cadavers . Int J Biol Med Res. 2013; 4(1): 2875-2878

7. Smith SD, Benton RS. A rare origin of the superior thyroid artery. Acta Anat (Basel). 1978;101(1):91-3.

8. Botelho JB, Cardoso Neto J, Dos Anjos GS \& et al. Relation between the external branch of the superior laryngeal nerve and the superior thyroid artery: a study in 101 nerves. Rev Col Bras Cir. 2009;36(3):187-92.

9. Sharma, A. Variation in the Origin of Superior Thyroid Artery and it's Relation with External Laryngeal Nerve: A Cadaveric Study. Academia Anatomica International. 2019; 5(1), 6-9

10. Ozgur Z, Govsa F, Celik S, Ozgur T. Clinically relevant variations of the superior thyroid artery: an anatomic guide for surgical neck dissection. Surg radiol anat 2009;31(3):151 


\section{Anitha d Shanthini; Anamalaus Superiar Thyraid Autery}

Copyright: ( $)$ the author(s), publisher. Academia Anatomica International is an Official Publication of "Society for Health Care \& Research Development". It is an open-access article distributed under the terms of the Creative Commons Attribution Non-Commercial License, which permits unrestricted non-commercial use, distribution, and reproduction in any medium, provided the original work is properly cited.

How to cite this article: Anitha B, Shanthini. Superior Thyroid Artery Arising From the Common Carotid Artery- Potential Source for Unpredicted Intraoperative Bleeding- A Cadaveric Case Report. Acad. Anat. Int. 2019;5(2):5-7.

DOI: dx.doi.org/10.21276/aanat.2019.5.2.2

Source of Support: Nil, Conflict of Interest: None declared. 